\title{
MÃES EM CÁRCERE: ESTRATÉGIAS, GARGALOS E ACESSO À JUSTIÇA PÚBLICA
}

\section{MOTHERS IN JAIL: STRATEGIES, BOTTLENECKS AND ACCESS TO PUBLIC JUSTICE}

\author{
Gustavo Samuel da Silva Santos \\ Universidade Estadual Paulista em Franca - Unesp Franca - (Franca, SP, Brasil) \\ Ana Gabriela Mendes Braga \\ Universidade Estadual Paulista em Franca - Unesp Franca - (Franca, SP, Brasil)
}

Recebimento: 14 set. 2019

Aceitação: 7 jan. 2020

\begin{abstract}
Como citar este artigo / How to cite this article (informe a data atual de acesso / inform the current date of access):
SANTOS, Gustavo Samuel da Silva; BRAGA, Ana Gabriela Mendes. Mães em Cárcere: estratégias, gargalos e acesso à justiça pública. Revista da Faculdade de Direito UFPR, Curitiba, v. 65, n. 2, p. 75-100, maio/ago. 2020. ISSN 22367284. Disponível em: https://revistas.ufpr.br/direito/article/view/69211. Acesso em: 31 ago. 2020. DOI: http://dx.doi.org/10.5380/rfdufpr.v65i2.69211.
\end{abstract}

\section{RESUMO}

O presente artigo tem por objeto o estudo da política Mães em Cárcere, por meio da análise documental da Deliberação 291/2014 do Conselho Superior da Defensoria Pública de São Paulo, que funda um atendimento especializado para as mães presas no estado. Partindo-se da constatação de que as prisões brasileiras vivem um "estado de coisas inconstitucional” e que a assistência jurídica no País é feita por meio de um modelo público, do qual dependem milhares de pessoas presas, em sua maioria negras e pobres, a política Mães em Cárcere é pensada como estratégica no âmbito da Defensoria Pública, centrada na atuação coordenada de seus vários órgãos, na sistematização de dados sobre o encarceramento das mães presas em São Paulo e na troca de experiências com a sociedade civil. Embora com toda a articulação e especialidade, essa estratégia não é o suficiente para alcançar todas as mães presas e garantir que seus direitos - principalmente, o direito à liberdade - sejam cumpridos. Ainda assim, ela teve um impacto no acesso das mães presas paulistas à justiça, parecendo ser um marco importante para se refletir sobre o encarceramento feminino no Brasil.

\section{PALAVRAS-CHAVE}

Maternidade. Prisão. Acesso à justiça. Mães em Cárcere. Defensoria Pública.

\begin{abstract}
This article has as its object the study of the policy Mães em Cárcere (Mothers in Jail) through the documentary analysis of Deliberation 291/2014 from Superior Council of the São Paulo Public Defender's Office, which brings specialized care for mothers imprisoned in the state. Based on the fact that Brazilian prisons represent an "unconstitutional state of affairs" and that legal assistance in the country is done through a public model, on which thousands of prisoners, mostly black and poor, are dependent, the policy Mães em Cárcere is thought of as strategic within the Public Defense, focused on the coordinated performance of its various agencies, systematization of data on the mothers imprisoned in São Paulo and on the constant exchange of experiences with civil society.
\end{abstract}


Despite all the articulation and specialty, this strategy is not enough to ensure that the rights especially the right to liberty - of imprisoned mothers are fulfilled; even so, it had an impact on the access to justice for mothers imprisoned in São Paulo, seeming to be an important milestone to reflect on the incarceration of women in Brazil.

\section{KEYWORDS}

Maternity. Prison. Access to justice. Mothers in jail. Public Defense.

\section{INTRODUÇÃO}

No ano de 2014, o Conselho Superior da Defensoria Pública de São Paulo, por meio da Deliberação 291, instituiu a política Mães em Cárcere, que sistematizou e organizou fluxos de atendimento para mães e mulheres grávidas encarceradas no estado.

Com a finalidade de debater essa política pública, desenvolveu-se um estudo de caso sobre a Mães em Cárcere, por meio de análise documental de normativas, atas de reuniões e registros documentais, além de entrevistas semiestruturadas com as personagens que articularam e trabalharam nos Núcleos Especializados da Defensoria e com representantes da sociedade civil organizada na época de instituição e consolidação da política. Para além da contribuição mais propositiva de descrição e análise da política pública, aposta-se nesse corte como uma chave interessante para pensar as experiências e concepções de acesso da mãe presa à justiça.

O recorte deste texto atende especialmente a análise da Deliberação 291/14 do Conselho Superior da Defensoria Pública de São Paulo, que instituiu a Mães em Cárcere. Entretanto, o corpus empírico da pesquisa não se esgota aí, compõe-se de uma série de outras fontes documentais, além de entrevistas com personagens envolvidas na criação da política - a serem trabalhadas em um outro momento da pesquisa -, localizando-o na discussão sobre acesso das mulheres à justiça, missão e formas institucionais da assessoria jurídica pública.

Situa-se a política Mães em Cárcere como uma política pública estratégica na Defensoria Pública para enfrentar obstáculos específicos das mães e grávidas encarceradas, incorporando em sua agenda decisória o encarceramento dessas mulheres.

Na primeira seção do texto - A última na fila depois de ninguém - a mãe encarcerada em um sistema inconstitucional -, parte-se da discussão da situação da maternidade na prisão e dos particulares obstáculos ao acesso à das mulheres justiça, que em análise de política pública é tida como a fase de identificação do problema.

Em seguida, na seção A verde esperança: a Defensoria Pública e o acesso à justiça, detémse sobre o modelo público de acesso à justiça no estado de São Paulo e suas implicações, 
compreendendo aspectos da Defensoria Pública paulista que permitiram a incorporação das demandas das mães encarceradas como prioritárias na agenda da instituição.

Na terceira seção - Saindo das sombras - a política Mães em Cárcere da Defensoria Pública de São Paulo - analisa-se a Deliberação 291/14 do Conselho Superior da Defensoria Pública paulista, documento-chave para compreender a implantação da política pública, observando aspectos estratégicos na sua formulação, como a apresentação dos seus motivos de forma preambular, a formulação de uma comunicação interna para uma ação concatenada e, por fim, a produção de dados e o diálogo para além da instituição na disputa de sentidos para a efetivação do direito das mães encarceradas.

Ao final, pensa-se a ação da Defensoria em marcos de estratégia que dá visibilidade e sistematiza o fluxo do acesso da mãe encarcerada à justiça; e, ainda, nas limitações e desafios de sua implementação.

\title{
1 A ÚLTIMA NA FILA DEPOIS DE NINGUÉM ${ }^{1}$ - A MÃE ENCARCERADA EM UM SISTEMA INCONSTITUCIONAL
}

O sistema penitenciário brasileiro é reconhecidamente um fracasso quanto aos seus objetivos declarados, mas tem funcionado na produção de hierarquias de poder e de mortes, grandes e pequenas, com cerca de 800 mil pessoas, a maioria negras, e cada vez mais mulheres. A superlotação é uma regra. De acordo com o Infopen (BRASIL, 2017), a taxa de ocupação média das unidades prisionais era de 196\% em 2016, sendo que no Amazonas, a taxa era de 484\% na mesma época. No mesmo relatório, aponta-se que apenas 12\% dos presos brasileiros tinham acesso a atividades educacionais e apenas 15\% da população carcerária tinham acesso ao trabalho.

Perante o quadro de precariedade e violência institucional que caracteriza o sistema prisional brasileiro, o Supremo Tribunal Federal, ao julgar as medidas cautelares na ADPF 347, entendeu que o sistema carcerário brasileiro vive um “estado de coisas inconstitucional”, isto é, existe um quadro geral de violações aos direitos fundamentais no sistema penitenciário. Katya Kozicki e Bianca Van Der Broocke (2018, p. 172) comentam a decisão:

\begin{abstract}
Ao apreciar os pedidos de medida cautelar formulados na inicial, os Ministros reconheceram a existência de um quadro de violação massiva e persistente de direitos fundamentais, decorrente da falência de políticas públicas e de falha estrutural, representada pela ausência de medidas legislativas, administrativas e orçamentárias eficazes, cuja modificação depende de um conjunto de soluções que envolva a atuação coordenada de entes públicos dos diferentes níveis federativos, declarando o ECI do sistema penitenciário nacional.
\end{abstract}

1 Expressão utilizada por Sueli Carneiro, importante feminista negra, segundo Dina Alves (2017, p. 107). 
Sobrevivem nesse caos, majoritariamente, jovens (55\% da população carcerária, segundo o já citado relatório do Infopen, têm até 29 anos), negros (64 \%), com baixa escolaridade (75\% não acessaram o ensino médio). 40\% dos presos o estão preventivamente. O relatório ainda estimou o número de 716.712 pessoas presas em 2016, das quais cerca de 42 mil eram mulheres.

Apesar de em menor número no cárcere, o Infopen Mulheres (BRASIL, 2018) demonstra que desde o início deste século, o número de presas aumentou 456\%, enquanto a população carcerária masculina aumentou cerca de 293\% no mesmo período. Comparando com outros países, observa-se a explosão do crescimento no encarceramento feminino no País. A segunda maior variação do número de mulheres na prisão entre 2000 e 2016 foi na China, com aumento de 105\%. Na Rússia, um dos países com o maior número de presos do mundo, o número de mulheres encarceradas caiu 2\% no período.

A taxa de ocupação dos estabelecimentos prisionais para mulheres também é alta - cerca de 157\% em 2016, isto é, para cada 10 vagas, havia cerca de 16 mulheres encarceradas. O Infopen demonstra uma distribuição desigual das presas. Cerca de 37\% dos estabelecimentos prisionais não eram superlotados e 11\% tinham mais de quatro presas por vaga. Metade das mulheres presas em 2016 eram jovens, 62\% eram negras e 66\% não tiveram acesso ao ensino médio.

O acesso a serviços básicos é difícil para as mulheres. Apenas 25\% tiveram acesso a alguma atividade educacional e cerca de $24 \%$ conseguiram acesso ao trabalho. O número de ginecologistas é ínfimo, apenas 28 médicas em todo o sistema prisional nacional, sempre de acordo com o Infopen Mulheres (BRASIL, 2018). Para além das estatísticas oficiais, uma das manifestações das diferenças de gênero observadas entre o encarceramento de homens e mulheres é o número reduzido de visitas às últimas. O relatório produzido por diversas organizações, entre elas o Instituto Terra, Trabalho e Cidadania (ITTC, SP) e a Pastoral Carcerária, aponta para o isolamento de significativa parcela de mulheres presas:

A mulher presa apresenta uma grande preocupação em relação aos parentes, vizinhas ou instituições que estão criando seus filhos. A perda do vínculo com a família é uma constante preocupação da mulher presa. Cerca de $47 \%$ delas não recebem visitas ou as recebem menos de uma vez por mês (CENTRO PELA JUSTIÇA E PELO DIREITO INTERNACIONAL et al., 2018).

Mesmo organismos internacionais tardaram a reconhecer e a regular as necessidades peculiares da mulher no cárcere. As regras mínimas para o tratamento do preso foram aprovadas em 1957 pela ONU, enquanto apenas no ano de 2010, com as Regras de Bangkok, houve um documento específico que regulava internacionalmente as diretrizes para o tratamento das mulheres presas. 
Foram mais de cinquenta anos para que se proclamasse oficialmente em âmbito global que as mulheres presas necessitavam de atenção específica.

Renato Dagnino, Paula Arcoverde Cavalcanti e Greiner Costa (2016) explicam que a não tomada de decisão é tão significante para a análise de políticas públicas quanto as decisões efetivamente realizadas, refletindo valores e relações de poder que evitam que alguns temas sejam incorporados à agenda governamental.

Sobre o tema, é pertinente retomar as reflexões presentes na pesquisa Dar à Luz na Sombra, financiada pelo Ministério da Justiça, que objetivou investigar as condições atuais e possibilidades futuras do exercício da maternidade em situação de prisão, apontando para o caráter antropocêntrico do sistema de justiça:

Considerando que o direito vem sendo constituído basicamente a partir de experiências masculinas, seu caráter antropocêntrico alcança e conforma inclusive o lugar das mulheres como personagens do sistema de justiça, sejam elas presas, juízas, promotoras, agentes etc. O sistema de justiça enquanto heteronormativo assinala um lugar social para a mulher inferiorizado e excepcional em relação ao homem. As políticas, as instituições, as leis são pensadas a partir do homem, e adaptadas às necessidades e especificidades do encarceramento feminino (BRASIL, 2015a, p. 21).

A situação da mãe encarcerada é ainda mais complexa. Além das mazelas vividas pela população carcerária em geral e do esquecimento das peculiaridades do seu gênero, a mulher grávida ou mãe enfrenta outras dificuldades, como falta de acompanhamento pré-natal adequado, desumanização do parto, falta de informação sobre a situação dos filhos, acesso precário à justiça, etc.

Há que se considerar que a “mãe infratora” representa um contrassenso no ideário cristão, em especial católico, tão arraigado na cultura brasileira. Silvana Ribeiro (2000) identifica duas representações do feminino a partir das religiões cristãs: a primeira baseada na imagem de Eva, identificada com a desobediência e o pecado, e a segunda na de Maria, ligada à virtude e ao divino. Para Silvana Ribeiro, Maria, na tradição católica, é a representação do que a mulher deveria ser, algo inatingível, visto a natureza divina dela, mas um exemplo a ser continuamente perseguido, apresentando três figuras da mulher ideal católica: a mãe, a esposa e a virgem:

Como vimos, a maternidade (encarnada por Maria) assume-se como forma de permitir a salvação do sexo feminino e de o redimir do pecado da sua mãe Eva, desde que o comportamento das mulheres permaneça dentro de outros parâmetros adicionais de perfeição (RIBEIRO, S., 2000, p. 12).

Citando a primeira carta de Paulo à Timóteo, Silvana Ribeiro (2000) identifica três prescrições do catolicismo à conduta das mulheres: fé, caridade e santidade, as mesmas que os textos 
bíblicos indiciam como características da Virgem Maria. Entretanto, segundo a citada autora, a mulher na tradição católica é, essencialmente, Eva, a pecadora. O pecado é associado à desobediência feminina, ao seu caráter enganador aglutinado ao corpo sensual e belo:

Estabelece-se, assim, uma visão da mulher que aglutina beleza, por um lado, e um carácter enganador e indigno de confiança, por outro. Traços arquétipos do feminino são encarnados por Eva (e por todas as mulheres) e enformam as atitudes morais face à sua mente e aparência (RIBEIRO, S., 2000, p. 13).

A mãe encarcerada pode ser localizada no encontro dessas duas representações. A criminosa, pecadora, desobediente, mas, ao mesmo tempo, criadora da vida, em seu momento mais próximo das expectativas relacionadas ao gênero feminino. No sistema de justiça criminal, entretanto, essa contradição é resolvida com a imagem da criminosa se sobrepondo a todas as outras. O crime e sua punição aparecem como prioritários, justificando a manutenção da mulher no cárcere e mesmo sua separação dos filhos.

A representação criminosa se sobrepõe às outras. [...]. No campo de pesquisa identificamos uma ausência de escuta da mulher acerca de seus desejos e suas possibilidades. A categoria criminosa basta para deslegitimar a presa como boa mãe, logo, a decisão não leva em conta o contexto específico daquela mulher ao blindar suas possibilidades de exercício da maternidade (BRASIL, 2015a, p. 21).

Uma das principais conclusões da pesquisa Dar à Luz na Sombra é a de que as maiores angústias das mães encarceradas se referem à própria liberdade e sua situação processual:

Nas visitas que realizamos aos estabelecimentos prisionais femininos brasileiros, foi comum as presas afirmarem que não tinham advogada ou que não a conheciam - colocando em xeque a garantia constitucional da ampla defesa. Como não existe processo penal sem defesa técnica, pode-se concluir que as presas, de modo geral, não têm contato com sua defensora pública, dativa ou constituída (BRASIL, 2015a, p. 73).

Essas angústias remetem à precariedade no exercício do direito ao acesso à justiça, tema que obriga, inclusive pelo previsto na Constituição Federal, a análise da instituição Defensoria Pública e seu papel na prestação de assistência jurídica integral e gratuita para pessoas em situação de vulnerabilidade.

\section{A VERDE ESPERANÇA²: A DEFENSORIA PÚBLICA E O ACESSO À JUSTIÇA}

O direito à assistência jurídica foi consagrado como fundamental na Constituição Federal de 1988, mais precisamente no art. 50, inciso LXXIV, devendo ser integral e gratuito àqueles que

2 Verde é a cor que simboliza a Defensoria Pública. 
demonstrarem insuficiência de recursos. A Lei Fundamental brasileira, entretanto, não se restringe a apenas declarar esse direito, mas previu, desde sua promulgação, como ele será exercido: por meio da Defensoria Pública, conforme o art. 134.

O texto original apenas previa a Defensoria Pública como responsável pela orientação jurídica e defesa dos necessitados. A Emenda Constitucional 80/2014, entretanto, aperfeiçoou o conceito de Defensoria Pública e, por consequência, o conceito de assistência jurídica, apontando essa como instituição essencial à justiça, permanente, expressão do regime democrático, cabendo-lhe a promoção de direitos humanos, a orientação e a defesa, seja judicial seja extrajudicialmente, dos direitos individuais e coletivos dos mais necessitados.

Caio Paiva (2015) assinala que a Emenda Constitucional 80/04 dá um novo perfil constitucional à Defensoria Pública, elevando-a a um novo patamar normativo, com explicitação ampla do seu conceito e missão.

O regramento infraconstitucional das defensorias públicas é feito pela Lei Complementar 80/94, que sofreu significativa alteração pela Lei Complementar 132/09, adequando-a às mudanças produzidas pela citada emenda constitucional.

Thiago Fensterseifer (2017) aponta que o tratamento constitucional atual e as alterações legislativas recentes são qualitativamente diferentes do previsto nas constituições anteriores à de 1988, não só por prever a Defensoria Pública como instituição responsável pelo acesso dos mais necessitados à justiça, mas por garantir não apenas a assistência judiciária, limitada ao acesso ao Poder Judiciário, com redução de custos e simplificação de procedimentos, mas a assistência jurídica, que além do acesso ao Poder Judiciário, também engloba assistência extrajudicial integral, pré e pósjudicial, com educação em direitos e atendimento multidisciplinar. O art. $4^{\circ}$ da Lei Complementar 80/94 prevê mais de vinte funções institucionais da instituição, entre elas promover solução extrajudicial de conflitos, prestar atendimento interdisciplinar, promover ações coletivas para grupos vulneráveis, participação em conselho de direitos e convocar audiências públicas.

A Defensoria Pública se insere no modelo público de assistência jurídica apontada por Mauro Cappelletti e Bryant Garth (1988) no clássico Acesso à Justiça, livro que introduziu os resultados do Projeto Florença ${ }^{3}$, que analisou os obstáculos, e as soluções construídas, para o acesso à justiça.

3 O Projeto Florença consistiu em uma grande mobilização de pesquisadores empíricos de diversos ramos das ciências sociais para a coleta de dados sobre o sistema de justiça de diversos países na década de sessenta e setenta e teve como consequência a proliferação de estudos sobre o acesso à justiça (PORTO, 2009). 
Cappelletti e Garth (1988) indicam que inicialmente o acesso dos mais pobres à justiça era promovido por advogados particulares, sem contraprestação, reconhecendo-se o direito ao acesso, mas sem qualquer ação estatal para sua garantia.

Com as evidentes deficiências desse modelo, em especial em economias de mercado, vários países europeus passaram a adotar o sistema judicare, em que a assistência judiciária era promovida por advogados particulares, mas que seriam remunerados pelo Estado. O sistema judicare, entretanto, segundo os autores, é eficiente para desfazer a barreira do custo, mas faz pouco para atacar outros obstáculos além da pobreza, como a falta de conhecimento sobre direitos e a necessidade de litígios organizacionais, e trata os pobres como indivíduos apenas, não os reconhecendo como classe (e por consequência não superando barreiras para ações de cunho coletivo).

O último modelo apresentado por Cappelletti e Garth (1988) é o de advogados remunerados pelos cofres públicos, que na sua gênese contava com escritórios de vizinhança, no Programa de Serviços Jurídicos do Office of Economic Opportunity, de 1965, em que eram montados escritórios de advocacia nas comunidades pobres, onde eram estimulados a promover a consciência das pessoas pobres sobre seus direitos, litigar estrategicamente, com ações coletivas e, inclusive, praticando lobbies para reforma da legislação em favor dos seus assistidos.

Citando o artigo 134 da Constituição Federal brasileira, Franklyn Roger Alves Silva e Diogo Esteves (2019) apontam que o Brasil adotou o último modelo apontado pela pesquisa coordenada por Cappelletti e Garth (1988) - o de advogados remunerados pelos cofres públicos - ante a existência de um corpo de profissionais concursados e efetivos para a prestação direta de serviços jurídicos administrativos.

Para melhor compreensão do regime público de assistência jurídica brasileira, Fensterseifer (2017) entende como oportuno entender o lugar da Defensoria Pública no âmbito do sistema de justiça: a advocacia pública, que é compreendida como: a) a defesa do interesse público (de atribuição do Ministério Público); b) a defesa do público (função da Defensoria Pública); c) defesa do governo (função da advocacia pública stricto sensu, como as procuradorias). Isso significa que o defensor público é figura diferente da do advogado inscrito no OAB, inclusive, por força do art. $134, \S 1^{\circ}$, da Constituição Federal, já que não pode exercer a advocacia privada, tendo funções, como apontado acima, que vão além da mera representação jurídica.

Fensterseifer (2017) insiste que a Defensoria Pública é consequência dos objetivos constitucionais previstos no art. $3^{\circ}$ da Constituição brasileira, notadamente a construção de uma sociedade livre, justa e solidária, a erradicação da pobreza e marginalização e redução das desigualdades sociais e regionais. A preocupação com a atuação estratégica, com a compreensão de 
que a atuação na assistência jurídica não se limita a violações individuais de direitos, mas encarando os vulneráveis como grupo, pode ser percebida com a possibilidade de organização das defensorias públicas, prevista na Lei Complementar 80/94, por meio de núcleos especializados.

Nesse sentido se manifestou o Ministério da Justiça no IV Diagnóstico da Defensoria Pública (BRASIL, 2015b, p. 11), apontando os núcleos da Defensoria Pública como responsáveis por introduzir, no âmbito da representação jurídica, inovações como as experiências de incubação de tribunais de conciliação, estratégias de orientação e enfrentamento à violência doméstica. E, os núcleos de direitos humanos, tidos como fundamentais para inúmeras comunidades periféricas, ocupações urbanas e grupos sociais minoritários.

O modelo público de assistência jurídica aperfeiçoado no Brasil não apenas compreende o pobre como classe, para usar a expressão de Cappelletti e Garth (1988), como objeto de proteção, mas insere a população na sua própria estrutura, como na previsão de uma ouvidoria-geral pela Lei Complementar 80/94, ou na previsão do ciclo de conferências, pela Lei Complementar Estadual 988/06, da Defensoria Pública paulista, em que a população é chamada para apontar quais suas principais expectativas com a instituição e delinear os principais pontos do plano de atuação da defensoria no biênio seguinte.

Garantir a presença da população na fiscalização dos trabalhos da defensoria, com uma ouvidoria externa, ou mesmo na fixação de suas prioridades é rejeitar a ideia de que o assistido é incapaz. Luciana Zaffalon Leme Cardoso (2010) aponta que a introdução de mecanismos de controle e participação popular na Defensoria Pública de São Paulo, como a ouvidoria externa, o ciclo de conferências acima citado e o momento aberto, espaço disponível nas reuniões do Conselho Superior da Defensoria Pública de São Paulo para livre manifestação de qualquer pessoa, instituíram um novo paradigma participativo.

A construção desses mecanismos democráticos na Defensoria Pública paulista pode ser relacionada com a criação da instituição no estado de São Paulo, fruto de intensa mobilização popular. Eneida Haddad (2011) aponta que os serviços de assistência jurídica eram prestados, desde 1947, pela Procuradoria de Assistência Judiciária (PAJ), um órgão da Procuradoria Geral do Estado, o que gerava intensos conflitos de interesse, já que em vários momentos a PAJ demandava contra o estado de São Paulo, representado juridicamente pela Procuradoria Geral do Estado.

Com a previsão constitucional, o anseio popular por acesso à justiça e a articulação do Movimento pela Defensoria Pública do Estado de São Paulo, estavam criadas as condições para o estabelecimento da instituição no estado. O Movimento pela Criação da Defensoria Pública tornouse um processo sem volta quando entidades que militavam pela defesa da infância e juventude, pelos 
direitos humanos, da moradia e na área criminal, passaram a exigir que São Paulo também organizasse uma defensoria pública nos termos do art. 134 da Constituição Federal. Em determinado momento, havia mais de 400 entidades endossando o movimento.

A defensoria paulista se estruturou de forma democrática, com formação continuada, atendimento multidisciplinar e atuação estratégica. Nesse sentido, Soares (2011) identifica alguns órgãos desta instituição de singular importância em sua estrutura. Entre eles destacam-se: o Conselho Superior, que tem entre seus membros representantes do nível inicial da carreira de defensor público e, com direito a voz apenas, um ouvidor externo; a Escola da Defensoria Pública de São Paulo (Edepe), que promove cursos de capacitação que vão além da mera dogmática, fomenta atividades de educação em direitos para toda a comunidade e a pesquisa científica produzida por defensores públicos e servidores; os núcleos especializados, que atuam em demandas estratégicas e advindas, especialmente, de setores organizados da sociedade civil, como ONGs, associações e coletivos populares.

Essas estruturas permitem que dentro da Defensoria Pública seja possível que atores externos influenciem na construção da agenda governamental e decisória da instituição, que, segundo Milena Pavan Serafim e Rafael de Brito Dias (2012), são, respectivamente, os assuntos tidos como importantes para o governo e os prioritários, alvo de maiores esforços da administração para a construção de políticas públicas, isso porque, de acordo com os mesmos autores, na formulação de uma política pública, a transformação de um modelo cognitivo depende das relações de poder dos conflitos que dela decorrem, que podem ter natureza explícita, ser um conflito aberto, envolvido em um processo de tomada de decisão para uma política pública, ou encoberto, isto é, afastado da agenda, criando uma situação de não tomada de decisão.

Assim, as interlocuções com a sociedade civil e a busca por uma atuação estratégica, integral e eficiente provocou, entre outras medidas na Defensoria Pública, a criação da política Mães em Cárcere, como um meio para oferecer às mulheres grávidas e mães presas no estado de São Paulo assistência jurídica adequada às suas necessidades, em especial quanto ao direito à convivência familiar dela e de seus filhos.

\section{SAINDO DAS SOMBRAS: A POLÍTICA MÃES EM CÁRCERE DA DEFENSORIA PÚBLICA DE SÃO PAULO}

Mães em Cárcere é a política de atendimento da Defensoria Pública do Estado de São Paulo para mulheres presas que estejam grávidas, sejam mães de filhos com até 17 anos ou que sejam 
pessoas com deficiência ou com alguma outra vulnerabilidade que demande atendimento específico, segundo o art. $1^{\circ}$ da Deliberação 291/14 do Conselho Superior da Defensoria Pública do Estado de São Paulo.

A política surge após experiência da Pastoral Carcerária, que promovia atendimentos jurídicos às mães encarceradas (PASTORAL CARCERÁRIA DO ESTADO DE SÃO PAULO, 2014), nos quais identificava omissões ou ações ilegais do Estado em desfavor de grávidas e mães encarceradas. A Pastoral Carcerária, assim, envidou esforços para que seus atendimentos jurídicos fossem transformados em política pública pela instituição responsável por garantir acesso à justiça às presas.

A instituição religiosa explica a necessidade de transformação de suas ações pontuais em política pública com um caso, em notícia que comentava a aprovação da Deliberação 291/14 do Conselho Superior da Defensoria Pública de São Paulo, em que se conseguiu a garantia da convivência familiar para uma criança acolhida por ter a mãe encarcerada, após atuação da Defensoria Pública:

\footnotetext{
Após o atendimento jurídico de uma mãe que era ré em processo de destituição do poder familiar e cujo filho estava em entidade de acolhimento institucional, foi possível obter a informação de que a avó da criança poderia ficar com o neto durante o período de privação de liberdade. A defensora que atuava no caso informou isso no processo e a criança retornou para o convívio familiar (PASTORAL CARCERÁRIA DO ESTADO DE SÃO PAULO, 2014).
}

Situações como essa ilustram a necessidade de uma política sistemática de acesso à justiça para mães encarceradas. A criança e a mulher presa citados acima, por muito pouco, não foram privadas do seu direito à convivência familiar, mesmo existindo formas adequadas para garantir esse direito, como a permanência do infante na família extensa. Sem acesso à justiça integral, a mulher encarcerada não poderia se contrapor ao acolhimento desnecessário do seu filho, porque não poderia, por exemplo, falar diretamente com as equipes de acolhimento, não sendo raras as vezes em que as mães não sabem sequer onde está o próprio filho.

A seletividade do sistema penal e a "guerra às drogas” produz o perfil da maioria das mães encarceradas: pobres, negras, com pouco tempo de ensino formal, com várias barreiras para acessar o Judiciário e tendo de enfrentar ilegalidades estatais na garantia de seus direitos, notadamente o da convivência familiar, saúde e liberdade. Dessa maneira, o estudo da Mães em Cárcere desvela funcionamentos próprios do sistema de justiça e seus gargalos, para pensar, além do acesso à justiça efetivo a essas mulheres, uma outra forma de se fazer justiça. 
Neste texto, foca-se a análise no conteúdo da Deliberação 291/14, especialmente nos fundamentos explicitados para a política Mães em Cárcere, nas suas rotinas e órgãos, com o intuito de, a partir da análise da instituição da assessoria jurídica pública, pensar, do ponto de vista estratégico, a ação da justiça e o acesso à justiça em relação a essas mulheres, bem como as limitações desses mecanismos.

\section{1 “CONSIDERANDO...” - AS RAZÕES PARA A POLÍTICA MÃES EM CÁRCERE}

A Deliberação 291/14 se inicia com uma série de considerandos que apontam as razões para a existência da Mães em Cárcere, que cumpre o papel de preâmbulo da norma interna da Defensoria Pública e que parece ser um dos primeiros recursos estratégicos dos atores que compuseram essa política para que a agenda do acesso das mães encarceradas à justiça fosse prioritária na instituição.

Registrar no próprio texto da norma os valores e missão da Defensoria Pública, marcos históricos na formulação da Mães em Cárcere, é garantir um registro permanente em um espaço privilegiado junto aos defensores públicos, servidores, sociedade civil e da necessidade dessa política.

Dentre os considerandos, destaca-se o registro da Carta de São Paulo como fundamento da política. O documento é resultado do seminário Mães do cárcere: construindo caminhos para a garantia da convivência familiar de mulheres e crianças, organizado em 2011 pela Pastoral Carcerária, Defensoria Pública e Tribunal de Justiça de São Paulo (SÃO PAULO, 2011).

O seminário pode ser visto como uma provocação aos principais atores do sistema de justiça criminal, como a Secretaria de Assistência Penitenciária, os magistrados, a Defensoria Pública e o Ministério Público, para que efetivassem políticas públicas que suprissem necessidades das presas de convivência com seus filhos, acompanhamento médico adequado, produção de dados para diagnóstico da convivência entre as presas e seus filhos, com um fórum permanente para a discussão do tema.

Serafim e Dias (2012) explicam que a identificação do problema não é algo objetivo, precisa ser reconhecido subjetivamente pelos atores que pensam e produzem a política pública, e ligada a uma série de fatores externos, como escândalos midiáticos, o impacto emocional do problema, a magnitude da população afetada, além de fatores internos, como os valores e características dos órgãos e membros da instituição.

Assim, o seminário foi um momento para que os conflitos gerados pelo encarceramento das mães e grávidas não permanecessem encobertos e fossem identificados como um problema para que 
o sistema de justiça e, em especial, a Defensoria Pública, empenhassem-se na criação de políticas públicas adequadas para o seu enfrentamento.

Ainda, dentre as razões para delineamento da política naquele momento, destaca-se:

CONSIDERANDO a dinâmica social patriarcal que opera uma divisão sexual do trabalho traduzida no aprisionamento de mulheres e homens em papéis sociais pré-definidos, destinando, assim, às mulheres, de forma quase exclusiva, a função social do cuidado com os filhos, no interior das famílias; [...] (SÃO PAULO, 2014).

Tal enunciado situa o direito de exercício à maternidade em um quadro mais amplo da produção de desigualdade de gênero, em conformidade com o que as teorias de gênero têm apontado. O texto mobiliza conceitos como gênero e patriarcado, os quais são chaves para a compreensão e atuação estratégica não só em relação à prisão de mulheres, mas também quanto às expectativas de gênero sobre as quais recaem - argumento desenvolvido nos trabalhos de Carol Smart (1989, p. 2), para a qual há uma convergência entre o direito e o que costuma ser chamado de “cultura masculina”, e por essa razão a lei seria um foco importante da luta feminista, não somente para buscar reformas legais, mas para desafiar o poder masculino.

O poder masculino é exercido pelo direito produzindo e reproduzindo hierarquias de gênero, e sobrepenalizando as mulheres, segundo Paula Cassol:

O que se percebe, é que as mulheres, quando entram em contato com o Poder Judiciário, ou são vítimas de violência doméstica ou sexual, ou são autoras de delitos que são duplamente penalizadas por serem condenadas a um sistema que foi criado por e para os homens. Por isso, torna-se urgente a necessidade de um olhar criminológico feminista, que incorpore o conceito de gênero na análise do sistema de justiça criminal (CASSOL, 2017, p. 8).

A política Mães em Cárcere não ignora, entretanto, outros marcadores sociais da diferença para identificar as mães e mulheres encarceradas em São Paulo, como a classe social, conforme se nota no seguinte considerando: "CONSIDERANDO o aumento do número de mulheres reclusas, bem como o perfil dessas mulheres, majoritariamente pobres, jovens e, em regra, responsáveis principais pelo sustento e cuidado dos filhos; [...]” (SÃO PAULO, 2014).

Angela Davis, em diálogo com Gina Dent, observa que há um perfil semelhante entre as presas em diversas regiões do mundo, como Estados Unidos, Europa e Brasil: mães, jovens, com pouca escolaridade. Ressaltou também o papel da própria prisão, e seu uso discursivo, na produção da população carcerária com o mesmo perfil ao redor do mundo (DAVIS; DENT, 2003).

Dina Alves (2017) aponta que, para além de desmasculinizar as narrativas sobre o universo prisional, é preciso ter em mente as especificidades da mulher presa, com uma análise interseccional de como raça, gênero e classe social compõem a categoria “mulher encarcerada”. Entretanto, a Mães 
em Cárcere por si só também não foi capaz de superar esses paradigmas, permanecendo violações a direitos das presas, identificados aqui como opressões de gênero, que se valem da maternidade para sua constituição.

Alfredo Henrique (2019) aponta que em São Paulo o prazo mínimo previsto para a amamentação, de seis meses segundo o art. 83, § $2^{\circ}$, da Lei de Execução Penal ainda é tratado como máximo, sendo que a Secretaria de Administração Penitenciária começa a preparar a criança para a separação a partir do quarto mês. O direito de cuidar dos filhos fora do cárcere, por meio, em especial, da prisão domiciliar, apesar do marco da primeira infância (Lei 13.257/16) e do Habeas Corpus Coletivo 143641, também não tem sido efetivado plenamente, apesar de toda a articulação promovida pela Defensoria Pública paulista.

No relatório MulhereSemPrisão do Instituto Terra, Trabalho e Cidadania, que acompanhou 213 mulheres presas em audiência de custódia nas cidades de São Paulo e Osasco entre dezembro de 2017 e maio de 2018, consta que de 125 mulheres presas, grávidas ou mães de crianças, 65 foram libertadas provisoriamente e cinco tiveram a prisão em flagrante relaxada. 55 foram presas preventivamente, sendo que 49 destas foram encaminhadas para a unidade prisional e a apenas seis foi garantido o direito à prisão domiciliar (ALMEIDA et al., 2019, p. 98-99).

Cristopher Abreu Ravagnani, Bruno Humberto Neves e Josielly Lima Ito (2019), analisando 168 habeas corpus que tramitaram no Tribunal de Justiça de São Paulo entre julho e dezembro de 2018 e que tinham por objeto a prisão domiciliar às grávidas e mães de crianças, informam que apenas $15 \%$ deles foram deferidos. As principais razões para o indeferimento eram a falta de prova da imprescindibilidade da presença materna, resguardo da ordem pública e reincidência específica.

\subsection{UNIR PARA RESISTIR - A ATUAÇÃO CONJUGADA DOS NÚCLEOS ESPECIALIZADOS DA DEFENSORIA PÚBLICA E O CONVIVE}

O direito à assistência jurídica efetiva deve ser integral, capaz de realmente responder às dificuldades enfrentadas pelo cidadão. No caso das mães presas, há um conjunto de demandas que precisam ser observadas pela Defensoria Pública: direito a um parto humanizado, direito à liberdade, à prisão domiciliar, a amamentar o filho, a ter convivência familiar, etc.

Ocorre que essas demandas não surgem concentradas em um único processo, ou mesmo em uma única comarca ou área de atuação, e isso cria um obstáculo na prestação da assistência jurídica integral, ante a divisão de trabalho realizada na própria defensoria. Cada defensor atua numa determinada região e em demandas específicas. Assim, haveria uma dificuldade considerável para 
prestar o atendimento adequado a uma mulher presa na capital, que precisasse de atendimento jurídico sobre sua execução criminal, ao mesmo tempo que precisasse ser defendida em uma ação de destituição familiar que tramitasse na comarca de Ribeirão Preto, por exemplo.

Em especial por envolver crianças em situação de vulnerabilidade, há a necessidade de atuação eficiente do defensor público em ações de destituição do poder familiar. O art. 163 do Estatuto da Criança e do Adolescente (Lei 8.069/90) prevê, inclusive, o prazo de 120 dias para a conclusão do procedimento de destituição do poder familiar. Por isso, Maíra Coraci Alves, em entrevista para Bruna Ribeiro, fala da importância da atuação rápida do defensor público em processos de destituição do poder familiar e de como a atuação da Defensoria Pública era pouco eficaz antes da política Mães em Cárcere:

Antes de o projeto ser criado, as mães recebiam assistência, mas a defesa vinha tarde, pois era preciso aguardar a intimação do juiz. "Devido à morosidade do processo, muitas vezes, quando íamos procurar as crianças, elas já não eram mais encontradas.” (RIBEIRO, B., 2017).

A lógica da política Mães em Cárcere é articular todos os órgãos da Defensoria Pública de modo que tenham acesso às informações necessárias, ou que saibam que a demanda existe, para adequadamente prestar o serviço público. Conforme seu art. $8^{\circ}$, a Deliberação 291/14 prevê um órgão específico para gestão informacional, o CONVIVE (órgão de assessoria técnica de gestão informacional da defensoria pública), que recebe, registra e encaminha os casos para o defensor responsável. Com isso, há servidores destinados apenas a organizar as demandas e distribuí-las para os vários defensores e servidores responsáveis pela atuação, mesmo que eles atuem em cidades diferentes.

O art. $9^{\circ}$ da referida deliberação também prevê que as demandas de atendimento serão recebidas por meio de formulários, provocação de defensores públicos, ONGs e entidades sociais, cartas, pedidos de familiares e pelos Centros de Atendimento Multidisciplinar. Expandir as possibilidades de alcance à Defensoria Pública é essencial para o efetivo acesso das mulheres presas à justiça. Como visto anteriormente, uma das principais dificuldades das mulheres presas é a falta de visitas e, portanto, o limitado contato com o mundo exterior à prisão. Assim, muitas das suas demandas podem demorar a serem encaminhadas à Defensoria Pública ou mesmo nem sequer serem conhecidas por uma defensora, em especial se esta não é a responsável direta pelo atendimento da sentenciada.

Retomando o exemplo anterior, o defensor da infância e juventude lotado em Ribeirão Preto teria muito mais dificuldade em saber da existência de família extensa do filho de uma presa na capital 
de São Paulo, já que não terá contato com ela. Com acesso a informações como a existência de familiares, seria possível contatá-los com antecedência, para que possam se manifestar nos autos, tentando-se evitar que o infante seja colocado em família substituta enquanto a mãe estiver presa.

Os formulários citados no art. $9^{\circ}$, inciso I, da Deliberação 291/144 podem ser encontrados no site da Defensoria Pública e são entregues pela unidade prisional às presas, por força de um convênio estabelecido entre a instituição e a Secretaria de Administração Penitenciária, e contêm uma rápida nota sobre o que é a política Mães em Cárcere, a Defensoria Pública e como contatá-la ${ }^{5}$. A política tem o potencial, assim, de ser conhecida por todas as mulheres mães e grávidas do estado, caso haja a atuação da defensoria em todos os estabelecimentos penitenciários femininos.

Entretanto, analisando-se os relatórios estatísticos da Mães em Cárcere (SÃO PAULO, 2018), percebe-se que mesmo com mais de cinco anos de atendimento, esse potencial não foi atingido, não havendo tanto o atendimento para a totalidade das mães encarceradas quanto a mesma atenção sistemática para adolescentes internadas, apesar da previsão na própria deliberação.

A política Mães em Cárcere, estruturada a partir da atuação conjunta de vários órgãos da Defensoria Pública, prevê a participação de vários núcleos especializados que, de alguma forma, tenham relação com os problemas enfrentados pelas mães presas, sendo eles o Núcleo da Situação Carcerária, da Infância e Juventude e o da Promoção e Defesa dos Direitos da Mulher.

Os Núcleos da Infância e Juventude e da Situação Carcerária prestam auxílio técnico aos defensores públicos responsáveis pelas demandas individuais e coordenam o CONVIVE. Ainda, atuam em casos criminais ou nas varas da infância e juventude relacionados a mulheres atendidas pela política em comarcas sem atuação direta da Defensoria Pública.

O Núcleo da Promoção e Defesa dos Direitos da Mulher também atua em casos nas varas de família em comarcas sem atuação direta da Defensoria Pública quando há interesse da mulher atendida pela política e organiza publicação anual dos dados colhidos pelo CONVIVE, com apoio da Edepe. Ainda, atua, sem limitar o Núcleo de Situação Carcerária ou o defensor natural, em ações coletivas quando há violação a direitos da mulher encarcerada. Por fim, em conjunto com os outros núcleos, busca promover política de educação em direitos, com a produção de cartilhas, por exemplo, sobre direitos das mães presas.

A organização estratégica da Defensoria Pública de São Paulo, com a articulação de vários de seus órgãos, para atuar de forma sistemática em todas as demandas das mães e mulheres grávidas

4 Os formulários podem ser acessados em https://bit.ly/321voUU.

5 O fluxo completo de atendimento da política Mães em Cárcere pode ser encontrado no site da Defensoria Pública de São Paulo, na seção “Convive-Mães em Cárcere”, na subseção “Histórico e Fluxo”: https://bit.ly/2Qbea1C. 
encarceradas, não parece ser possível em um modelo de assistência jurídica diverso do público, como o judicare. Cappelletti e Garth (1988) apontam, como já dito, que o sistema judicare resolve bem as barreiras financeiras do acesso à justiça, mas as limitações das mães e mulheres grávidas presas não se restringem aos custos. Elas têm dificuldade em se comunicar com seus defensores, em obter informações e documentos relevantes para sua defesa nos processos de execução penal ou envolvendo a guarda e o poder familiar dos filhos e, por vezes, nem sequer sabem onde e sob os cuidados de quem seus filhos estão.

O relatório com dados estatísticos da Defensoria Pública sobre a Mães em Cárcere (SÃO PAULO, 2018) com dados do ano de 2017 mostra que o CONVIVE fez 257 pedidos de documentos, obteve mais de 1.800 certidões de nascimento, além de entrar em contato com a rede de atendimento socioassistencial ou mesmo enviar servidor técnico para atender a própria assistida. Essas atividades não são comuns na advocacia privada, que, em geral, não dispõe de assistentes técnicos e núcleos especializados e só atuam mediante a procura e para a diligência acordada especificamente em contrato. Com um modelo público e com uma política pública especialmente pensada para as necessidades das grávidas e mães presas, há mais chances de que a assistência jurídica seja integral e efetiva.

O desenho institucional da política, aqui pensada como estratégia de comunicação e atuação coordenada dos diversos órgãos da Defensoria Pública, surge, como explicam Serafim e Dias (2012), com a identificação do próprio problema, sendo que a formulação da política dá à massa de dados colhida nessa fase o caráter de informação relevante, que é articulada com os valores e ideais dos atores envolvidos e, por fim, transformada em ações públicas.

Tereza Meirelles (2017) pondera, por outro lado, que, na prática, ainda falta bastante articulação entre as partes que compõem a Mães em Cárcere. Indica que na rotina do CONVIVE, há a triagem dos casos e seu encaminhamento para o defensor natural do caso, que fará os pedidos que entender necessários, existindo pouco diálogo posterior.

Assim, apesar de estimular a participação de vários núcleos especializados e de criar um órgão para gerenciar as informações das presas, não há na Deliberação 291/14 a previsão de rotinas para integração direta dos defensores públicos que atuem sobre o caso nas várias áreas, como a execução criminal e a infância e juventude, com o estímulo de troca de informações entre eles ou com assistentes sociais, psicólogos e outros técnicos. 


\subsection{SABER É PODER - A PRODUÇÃO DE DADOS NA POLÍTICA MÃES EM CÁRCERE}

No texto da Deliberação 291/14 aparece a preocupação da instituição na produção de dados sobre o encarceramento das mães e mulheres grávidas no estado de São Paulo e na avaliação da própria política pública. O núcleo especializado na promoção e defesa dos direitos da mulher tem como atribuição produzir publicação anual, com dados obtidos em relatórios semestrais sistematizados pelo CONVIVE.

Está previsto no art. $7^{\circ}$, inciso II, da deliberação, que servidores técnicos da Defensoria Pública sistematizarão dados, relatórios e diagnósticos técnicos e estatísticos, e que divulgarão as informações referentes aos atendimentos e encaminhamentos realizados. E o art. 17, em complemento aos comandos anteriores, prevê a obrigação do CONVIVE em sistematizar, analisar e divulgar as atividades desenvolvidas e os resultados obtidos.

Essa preocupação com a produção de dados sobre o encarceramento das mães e mulheres grávidas e com os resultados da política Mães em Cárcere está em sintonia com o previsto na seção IV das Regras de Bangkok, que prevê a obrigação dos Estados em pesquisa, planejamento, avaliação e sensibilização pública. A Regra 67 de Bangkok prevê que serão realizadas pesquisas sobre a relação entre delito e gênero, impactos do encarceramento feminino e características das mulheres infratoras.

A Regra 68 exige pesquisas especificamente sobre o impacto nas crianças causado pelo encarceramento de suas mães.

A pesquisa e a produção de dados sobre o encarceramento feminino e sobre mães encarceradas ganha especial importância para a atuação da Defensoria Pública porque, como visto acima, o sistema criminal e penitenciário é feito por homens e para homens. Dados específicos sobre as necessidades das mulheres são preteridos, inclusive, em pesquisas do Departamento Penitenciário Nacional.

No Infopen Mulheres (BRASIL, 2018), por exemplo, há informações em relação a apenas 7\% da população carcerária feminina sobre o número de filhos de mulheres presas - número insignificante para o planejamento de políticas públicas adequadas para mães encarceradas. Por outro lado, a Defensoria Pública de São Paulo, como se vê no relatório de dados estatísticos de 2017 (SÃO PAULO, 2018) da Mães em Cárcere, conseguiu identificar, por exemplo, o número de filhos por mãe encarcerada, onde estão os filhos das mulheres presas, se eles tem algum tipo de deficiência, quantos estão no período de amamentação, etc. - dados essenciais para se planejar quais ações são mais urgentes, com quais órgãos da rede de proteção é preciso uma interlocução maior, etc. 
Esses dados não podem, no entanto, ter circulação restrita e se prestarem apenas para a justificação da política. Devem ser articulados para se pensar expansões futuras da Defensoria Pública, repensar práticas da Mães em Cárcere, subsidiar ações junto aos Poderes Executivos para a efetivação de políticas públicas (em áreas como saúde, educação, convivência familiar, etc.) ou mesmo como argumento para lobby, em favor das mulheres encarceradas e seus filhos, no Poder Legislativo, devendo ser vistos como uma ferramenta estratégica para a disputa de sentidos sobre o encarceramento das mulheres, produzindo informações que fortaleçam a agenda pelo desencarceramento das mulheres, que inspirou a política Mães em Cárcere, na Defensoria Pública e fora dela.

\subsection{QUIS CUSTODIET IPSOS CUSTODES? ${ }^{6}$ - A SOCIEDADE CIVIL E A PRESTAÇÃO DE CONTAS NA POLÍTICA MÃES EM CÁRCERE}

Por fim, um último aspecto importante a se destacar da Deliberação 291/14 é a preocupação, ao menos do ponto de vista normativo, em mapear e debater os resultados da política. Assim, além da publicação dos dados e estatísticas produzidos pelo CONVIVE, o art. 18 da deliberação prevê a realização de audiência pública anualmente, organizada pela primeira Subdefensoria Pública Geral e pelos Núcleos Especializados da Infância e Juventude, Situação Carcerária e Promoção e Defesa dos Direitos da Mulher.

Essa forma de agir mostra que, a despeito dos temores de Cappelletti e Garth (1988) quanto à formação de instituições paternalistas com o modelo de advogados públicos, é possível que o modelo público, ao contrário, promova a autonomia daqueles a quem assiste e reforce o espírito democrático. Cardoso (2010) inclusive aponta que, além de legitimar a ação da Defensoria Pública, a democratização dos processos decisórios é instrumento para o enfrentamento das desigualdades:

A democratização dos processos decisórios existentes na DPESP implica à [sic] legitimação do exercício de sua função garantidora da cidadania dentro do Poder Judiciário na medida em que, através da participação social, passa a ser possível a reversão do quadro de exclusão característico da ordem jurídica que precisa ser superado tendo em vista o fortalecimento do Estado Democrático de Direito. Considera-se, à luz de nosso referencial teórico, a "participação" como instrumento para que as desigualdades possam ser enfrentadas na forma de questões prioritárias e possíveis soluções coletivas (CARDOSO, 2010, p. 168).

Os canais de participação democrática na Defensoria Pública podem ser concebidos como mais um aspecto do atuar estratégico da instituição. A definição de prioridades, o feedback sobre as

6 Frase do poeta romano Juvenal, que pode ser traduzida como “quem vigia os vigilantes?” (CHACON, 2013, p. 1). 
ações da política institucional, o conhecimento das demandas invisibilizadas por obstáculos à justiça, são mais efetivaos quando há concreta participação da sociedade civil.

Na gramática das políticas públicas, este é um momento de avaliação da política, que é, para Serafim e Dias (2012) um espaço que vai além da observação técnica dos resultados, mas uma ferramenta política e útil na formulação das políticas públicas, reconhecendo-as como fruto de um complexo processo de disputas, interesses e valores entre os atores sociais envolvidos.

Há, ainda, uma questão a ser levantada sobre as audiências, que merece uma análise mais acurada por outras vias que não a mera análise documental proposta no artigo. Trata-se de questionar se a Defensoria Pública consegue envolver efetivamente amplos setores da sociedade nessas audiências, principalmente as próprias mulheres e seus familiares. As mulheres-alvo das ações da Mães em Cárcere estão encarceradas em prisões espalhadas por todo o estado e muitas estão em prisão domiciliar com significativas restrições, por vezes impossibilitadas totalmente de se ausentar de suas residências.

Manter as mães encarceradas como mero público-beneficiário da política pública, sem pensar em alternativas para sua efetiva participação na construção da política, limita o potencial democrático antevisto com as audiências públicas, comprometendo a qualidade e efetividade da avaliação da política pública.

Nesse sentido, são salutares as reflexões de Patricia Hill Collins (2000), que aposta no poder, da mulher negra, de se autodefinir como um ato de validação como ser humano, independentemente inclusive do conteúdo dessa autodefinição. Suas experiências, na perspectiva da epistemologia feminista negra, que intercruzam diversos marcadores (no caso aqui estudado, o da maternidade, da raça, classe, encarceramento), produzem conhecimento essenciais para a constituição de conhecimento e de uma política pública emancipatória.

Para as familiares, é preciso considerar também os custos com transporte, a questão da acessibilidade de horários por conta do trabalho e de visitas às presas, além de considerar que esses familiares, muitas vezes, como demonstram os relatórios da Defensoria Pública sobre a política, têm sua rotina diária sobrecarregada, pois têm de cuidar dos filhos das encarceradas.

Por fim, é necessário também pensar em que medida a Defensoria Pública está disposta a modificar suas práticas devido às participações nas audiências públicas. Maíra Martinelli Rizzardi (2015), por exemplo, aponta para uma disputa sobre o caráter das decisões dos Ciclos de Conferência 
da Defensoria Pública, se vinculativos ou opinativos, e para o não cumprimento de algumas das deliberações ${ }^{7}$.

Dessa maneira, a abertura prevista na Deliberação 291/14 é importante passo para superar os riscos de uma instituição paternalista na promoção do acesso à justiça, mas sua mera existência não é suficiente. É necessário que a relação entre defensoria e sociedade seja permeável às demandas e necessidades da sociedade civil, para que a audiência pública prevista na normativa não seja um espaço que reforce as hierarquias do saber acerca da prisão.

\section{CONSIDERAÇÕES FINAIS: POLÍTICAS DE ACESSO DAS MULHERES À JUSTIÇA}

A ação desorganizada e pulverizada não é compatível com a estruturação da Defensoria Pública no Brasil. Como visto, o modelo público de assistência jurídica exige que se tenha uma compreensão global dos obstáculos que os vulneráveis têm à justiça, indo além de suas dificuldades financeiras e individuais para o acesso à justiça. Por essa razão, Lucas Ressurreição (2018) defende que a Defensoria Pública deve atuar de forma estratégica, maximizando a eficiência na garantia do acesso à justiça integral.

O conceito de estratégia pode ser extraído de teorias sobre ação militar e política. Raul François Martins (1983), resgatando historicamente o conceito de estratégia lembra que, até o século XIX, era uma ideia ligada à guerra, a ciência da guerra, sendo uma atividade abrangente e diretora, que define os rumos da campanha. Já pensando o conceito em tempos de paz, o autor indica que estratégia tem sido conceituada como coordenação e gestão de recursos. Esses conceitos orientam a pensar atuação estratégica como um atuar com um objetivo em mente, de forma coordenada e organizada, em diversas frentes, valendo-se de todos os recursos disponíveis.

Mas não se está em tempo de paz, produz-se a guerra às drogas, o genocídio e o aprisionamento da população negra - este atingindo especialmente as mulheres, seus filhos e filhas. Nesse contexto, propõe-se ler a política Mães em Cárcere como estratégica no âmbito da Defensoria Pública, centrada na atuação coordenada de seus vários órgãos, na sistematização de dados sobre o encarceramento das mães presas em São Paulo e na constante troca de experiências com a sociedade civil.

A autora cita como exemplo a aprovação de realização de audiências públicas, para monitoramento do cumprimento das deliberações dos Ciclos de Conferências, de forma trimestral, mas que essas audiências têm acontecido de forma irregular: a primeira, após a aprovação da proposta em dezembro de 2013, ocorreu em dezembro de 2014, e a seguinte, em julho de 2015. 
Os objetivos da Defensoria Pública se alinham aos objetivos da República previstos no art. $3^{\circ}$ da Constituição Federal, no sentido de construir uma sociedade livre, justa e solidária. A política Mães em Cárcere se constrói como a possibilidade de uma boa prática de atuação estratégica da Defensoria Pública paulista, com a produção de dados sobre o encarceramento feminino, estruturando-se para uma atuação integral em várias áreas e comarcas, para enfrentar os obstáculos às mães encarceradas no acesso à justiça e se apoiando na sociedade civil para fiscalizar sua própria atuação e auxiliar na fixação das prioridades a serem tomadas.

Entretanto, é possível identificar limitações à política. Seu alcance é limitado, ainda não foi universalizada para todas as presas do estado, em especial as adolescentes; não prevê rotinas para trocas diretas entre os diferentes defensores que atuam diretamente em defesa das presas, para pensarem alternativas unificadas em defesa dos seus direitos; e, os espaços para participação popular na avaliação e controle da política não se apresentam como acessíveis para as principais interessadas: as mães encarceradas.

Também, por si só, a Mães em Cárcere não é suficiente para garantir direitos básicos de mães e filhos, como amamentação, convivência familiar e liberdade, ligados especialmente a questões de gênero, com o controle, pela administração da prisão e pelo Judiciário, do tempo e da forma como se exerce a maternidade.

Caio Santiago Fernandes Santos (2017), ao analisar a atuação da Defensoria Pública e os movimentos sociais, ressaltou os limites da promoção do acesso à justiça na garantia de direitos. A possibilidade de participação efetiva no Judiciário não garante o respeito a direitos, já que há outros fatores, além da lei, que influenciam nas decisões judiciais, como a opinião pública, destacando-se a necessidade de mobilização de grupos sociais para incidir nesses fatores, o que precisa ser levado em consideração pela Defensoria Pública para que a política Mães em Cárcere seja exitosa no enfrentamento a opressões de gênero, em especial as que mobilizam a maternidade para se constituírem.

Entretanto, mais do que pensar propositivamente a formulação da política, a análise da Mães em Cárcere permite refletir sobre a experiência da maternidade na prisão no Brasil e explorar as potencialidades e limites do modelo público de assistência jurídica. Além disso, ao se falar de especificidades de gênero no âmbito do sistema de justiça criminal, é fundamental construir caminhos para acesso à justiça a partir das concepções e experiências quanto a esse acesso elaboradas pelas mães presas, o que muitas vezes vai além do próprio limite institucional. 


\section{REFERÊNCIAS}

ALMEIDA, Maria Clara D’Ávila et al. MulhereSemPrisão: enfrentando a (in)visibilidade das mulheres submetidas à justiça criminal. São Paulo: Instituto Terra, Trabalho e Cidadania (ITTC), 2019. Disponível em: https://bit.ly/3h0tQkj. Acesso em: 12 jul. 2019d.

ALVES, Dina. Rés negras, juízes brancos: uma análise da interseccionalidade de gênero, raça e classe na produção da punição em uma prisão paulistana. Revista CS, Cali, v. 21, p. 91-120, 2017.

BRASIL. IV Diagnóstico da Defensoria Pública no Brasil. Brasília: Ministério da Justiça, Secretaria de Reforma do Judiciário, 2015b. Disponível em: https://bit.ly/3aqcJ99. Acesso em: 3 jun. 2019.

BRASIL. Ministério da Justiça e Segurança Pública. Departamento Penitenciário Nacional. Levantamento Nacional de Informações Penitenciárias. Atualização - junho de 2016. Brasília: Ministério da Justiça e Segurança Pública, Departamento Penitenciário Nacional, 2017. Disponível em: https://bit.ly/2DVYNb1. Acesso em: 2 jun. 2019.

BRASIL. Ministério da Justiça e Segurança Pública. Levantamento Nacional de Informações Penitenciárias. INFOPEN Mulheres. 2. ed. Brasília: Ministério da Justiça e Segurança Pública, Departamento Penitenciário Nacional, 2018. Disponível em: https://bit.ly/31ZrT16. Acesso em: 2 jun. 2019.

BRASIL. Ministério da Justiça. Secretaria de Assuntos Legislativos. Dar à luz na sombra: condições atuais e possibilidades futuras para o exercício da maternidade por mulheres em situação de prisão. Brasília: Ministério da Justiça, IPEA, 2015a. Disponível em: https://bit.ly/3h2r263. Acesso em: 2 jun. 2019.

CAPPELLETTI, Mauro; GARTH, Bryant. Acesso à justiça. Porto Alegre: Sergio Antônio Fabris Editor, 1988. 168 p.

CARDOSO, Luciana Zaffalon Leme. Participação Social: Inovações Democráticas no Caso da Defensoria Pública de São Paulo. 2010. Dissertação (Mestrado em Administração Pública e Governo) - Escola de Administração de Empresas de São Paulo, Fundação Getúlio Vargas, São Paulo, 2010.

CASSOL, Paula Dürks. Do gênero para além do gênero: a crítica feminista ao direito e à criminologia. In: Seminário Internacional Fazendo Gênero 11 \& 13th Women’s Worlds Congress, Florianópolis, 2017. Anais [...]. Florianópolis, 2017. Disponível em: https://bit.ly/3426iYx. Acesso em: 3 jun. 2019.

CENTRO PELA JUSTIÇA E PELO DIREITO INTERNACIONAL (CEJIL) et al. Relatório sobre Mulheres Encarceradas. Juízes para a democracia, São Paulo, 2018. Disponível em: https://bit.ly/2Y2EwY6. Acesso em: 2 jun. 2019.

CHACON, Eduarda. ECAD: Quis custodiet ispsos custodes? São Paulo, 2013. Disponível em: https://bit.ly/30ZNCH9. Acesso em: 29 jun. 2019. 
COLLINS, Patricia Hill. Black feminist thought: knowledge, consciousness, and the politics of empowerment. New York/London: Routledge, 2000. 335 p.

DAGNINO, Renato; CAVALCANTI, Paula Arcoverde; COSTA, Greiner. Gestão estratégica pública. São Paulo: Fundação Perseu Abramo, 2016. 491 p.

DAVIS, Angela; DENT, Gina. A prisão como fronteira: uma conversa sobre gênero, globalização e punição. Revista de Estudos Feministas, Florianópolis, v. 11, n. 2, p. 523-531, dez./2003.

FENSTERSEIFER, Tiago. Defensoria pública na Constituição Federal. Rio de Janeiro: Forense, 2017.

HADDAD, Eneida Gonçalves de Macedo. Os desígnios do Estado e a criação da Defensoria Pública do Estado de São Paulo. In: A Defensoria Pública do Estado de São Paulo: por um acesso democrático à Justiça. São Paulo: Letras Jurídicas, 2011. p. 23-120.

HENRIQUE, Alfredo. Veja como é a vida de grávidas e mães com bebês na cadeia. Agora São Paulo, 30 jun. 2019. Disponível em: https://bit.ly/2FjmsT1. Acesso: em 12 jul. 2019.

KOZICKI, Katya; VAN DER BROOCKE, Bianca Maruszczak Schneider. A ADPF 347 e o "Estado de Coisas Inconstitucional": ativismo dialógico e democratização do controle de constitucionalidade no Brasil. Direito, Estado e Sociedade, Rio de Janeiro, n. 53, p. 147-181, jul./dez. 2018. Disponível em: https://bit.ly/2DPutyW. Acesso em: 2 jun. 2019.

MARTINS, Raul François R. C. Acerca do conceito de estratégia. In: Nação e Defesa. Lisboa: IDP, 1983. p. 98-125. Disponível em: https://bit.ly/30WZfhQ. Acesso em: 3 jun. 2019.

MEIRELLES, Tereza. Análise de uma política pública. Política de Atendimento. Mães em Cárcere. Consejo Latinoamericano de Ciencias Sociales (CLACSO). Seminário de Políticas Públicas e Justiça de Gênero. Ago. 2017. Disponível em: https://bit.ly/31Urjlo. Acesso em: 18 dez. 2019.

PAIVA, Caio. EC 80/2014 dá novo perfil constitucional à Defensoria Pública. ConJur, [s. l.], 6 out. 2015. Disponível em: https://bit.ly/2DOcjxz. Acesso em: 2 jun. 2019.

PASTORAL CARCERÁRIA DO ESTADO DE SÃO PAULO. Experiência da pastoral carcerária inspira política de atendimento a mães presas em SP. Pastoral Carcerária, 12 mar. 2014. Disponível em: https://bit.ly/3g0SgZx. Acesso em: 18 dez. 2019.

PORTO, Júlia Pinto Ferreira. Acesso à justiça: projeto Florença e Banco Mundial. 2009.

Dissertação (Mestrado em Direito Político e Econômico) - Universidade Presbiteriana Mackenzie, São Paulo, 2009.

RAVAGNANI, Christopher Abreu; NEVES, Bruno Humberto; ITO, Josielly Lima. Mães encarceradas: apesar de contrariar STF, TJSP negou 85 \% dos pedidos de prisão domiciliar.

Justificando, [s. l.], 27 jun. 2019. Disponível em: https://bit.ly/30ZLVtl. Acesso em: 12 jul. 2019.

RESSURREIÇÃO, Lucas. Assistência jurídica e a atuação planejada e estratégica da Defensoria Pública. ConJur, [s. l.], 12 jun. 2018. Disponível em: https://bit.ly/3gZ8wvC. Acesso em: 30 jul. 2019. 
RIBEIRO, Bruna. Mães em cárcere: as dificuldades das mulheres presas e um projeto para atendêlas. Rede Peteca, [s. l.], 17 abr. 2017. Disponível em: https://bit.ly/3iL3jI9. Acesso em: 12 jul. 2019.

RIBEIRO, Silvana Mota. Ser Eva e dever ser Maria: paradigmas do feminino no Cristianismo. In: IV Congresso Português de Sociologia, 2000, Coimbra. Anais [...]. Coimbra: Universidade de Coimbra, 2000. Disponível em: https://bit.ly/3iICzrD. Acesso em: 2 jun. 2019.

RIZZARDI, Maíra Martinelli. Os ciclos de conferência da Defensoria Pública do Estado de São Paulo: controle e participação social. 2015. Dissertação (Mestrado em Direito) - Escola de Direito de São Paulo, Fundação Getúlio Vargas, São Paulo, 2015.

SANTOS, Caio Santiago. Defensoria Pública e movimentos sociais: novas possibilidades de acesso à Justiça no Brasil. Curitiba: Juruá, 2017. 146 p.

SÃO PAULO (Estado). Defensoria Pública do Estado de São Paulo (DPESP). Deliberação CSDP $\mathbf{n}^{\circ}$ 291, de 14 de fevereiro de 2014. Organiza a política institucional de atendimento às mulheres presas visando assegurar gestação segura e o exercício da maternidade durante o período da custódia penal, bem como a garantia, com prioridade absoluta, dos direitos das crianças e dos adolescentes. Disponível em: https://bit.ly/3iKDibS. Acesso em: 2 jun. 2019.

SÃO PAULO (Estado). Defensoria Pública do Estado de São Paulo (DPESP). Mães em cárcere. Dados estatísticos 2017. São Paulo, 2018. Disponível em: https://bit.ly/3iHFD7x. Acesso em: 3 jun. 2019.

SÃO PAULO (Estado). Pastoral Carcerária; Defensoria Pública do Estado de São Paulo e Ministério Público de São Paulo. Carta de São Paulo. Mães do Cárcere: construindo caminhos para a garantia da convivência familiar de mulheres e crianças. Elaborada por: Pastoral Carcerária; Defensoria Pública do Estado de São Paulo e Ministério Público de São Paulo. São Paulo, 2011. Disponível em: https://bit.ly/3asVBPR. Acesso em: 18 nov. 2019.

SERAFIM, Milena Pavan; DIAS, Rafael de Brito. Análise de política: uma revisão da literatura. Cadernos de Gestão Social, Salvador, v. 3, p. 121-134, jan./jun. 2012.

SILVA, Franklyn Roger Alves; ESTEVES, Diogo. O modelo brasileiro de assistência jurídica estatal gratuita. ConJur, [s. l.], 5 fev. 2019. Disponível em: https://bit.ly/2PTxEHZ. Acesso em: 3 jun. 2019.

SMART, Carol. Feminism and the power of law. London: Routledge, 1989.

SOARES, Thaís Aparecida. A Atuação da Defensoria Pública do Estado de São Paulo: A Construção de um modelo inovador. In: A Defensoria Pública do Estado de São Paulo: por um acesso democrático à Justiça. São Paulo: Letras Jurídicas, 2011. p. 177-250. 
Gustavo Samuel da Silva Santos

Mestrando em Direito

9Lattes iD: http://lattes.cnpq.br/0271313281232128

E-mail: gustavosamueldasilva@hotmail.com

Ana Gabriela Mendes Braga

Doutora em Direito Penal e Criminologia

9Lattes iD: http://lattes.cnpq.br/2586480165949878

E-mail: professora.anagabriela@gmail.com 